Feminist Attitudes Among African American Women and Men

By: Andrea G. Hunter, Sherrill L. Sellers

Hunter, A. G., \& Sellers, S. (1998). Feminist attitudes among African American women and men. Gender \& Society, 12(1), 81-99.

Made available courtesy of Sage Publications:

http://gas.sagepub.com/content/12/1/81.abstract

*** Reprinted with permission. No further reproduction is authorized without written
permission from Sage Publications. This version of the document is not the version of
record. Figures and/or pictures may be missing from this format of the document. ***

Abstract:

Research on the intersection of race and gender suggests that for African Americans, racial inequality is more salient than gender inequality. However theoretical perspectives on the multiplicative effects of status positions and "outsider within" models suggest that minority group membership can be a catalyst for the development of feminist attitudes. This article examines three issues central to feminism: (1) recognition and critique of gender inequality, (2) egalitarian gender roles, and (3) political activism for the rights of women. The authors found that support for feminist ideology was common for both African American women and men, although the level of support varied depending on the issue and by gender Factors predicting the endorsement of feminist ideology also varied depending on the issue and by gender The authors found partial support for the race saliency hypothesis, but there was also evidence of the multiplicative effects of status positions on African Americans feminist attitudes.

Keywords: Feminist Ideology | Race | African Americans | Gender Roles

\title{
Article:
}

The political alliances and tensions between the civil rights movement and the women's movement illustrate how race consciousness and feminism can both converge and be at odds (Giddings 1984; hooks 1981; King 1988; Terrelonge 1984). Although these social movements have in the past shared common aims, competing political interests and priorities have also divided them. Indeed, much of the public debate about race and feminism within the African American community has focused on the question of divided loyalties (Giddings 1984; King 1988; King 1975; Robinson 1983). However, theoretical perspectives on the multiplicative effects of status position and "outsider within" models suggest that minority group membership may be a catalyst for the development of feminist attitudes (Collins 1991; King 1988; Ransford and Miller 1983). Moreover, national studies by Gooley (1989) and Kane (1992) have found that African Americans are more likely to support feminist positions than white Americans of either gender. To better understand African Americans' support for feminist ideology, this article 
examines factors that influence African American attitudes on three issues central to feminism: (1) recognition and critique of gender inequality, (2) egalitarian gender roles, and (3) political activism for the rights of women.

\section{FEMINISM AND FEMINIST ATTITUDES AMONG AFRICAN AMERICAN WOMEN AND MEN}

Over the past fifteen years, a large body of work has explored the contours of African American feminist thought (e.g., Collins 1991; Combahee River Collective 1982; hooks 1981; King 1988). Black feminist epistemology is viewed as grounded in the intellectual traditions and experiences of African American women forged at the margins of race, gender, and class. Empirical studies also indicate that Black women's gender role attitudes are largely consistent with feminist ideology (Figueira-McDonough 1985; Ransford and Miller 1983; Wilcox 1989, 1990). They tend to have egalitarian gender role attitudes and are more likely to support collective political action for women than are white men or women (Gooley 1989; Kane 1992). Although African American women tend to be sympathetic toward issues of gender inequality, Wilcox (1989, 1990) argues that relatively few are full-fledged feminists (i.e., support feminist positions across the board). Furthermore, like American women generally, a minority of Black women identify themselves as feminist (Giddings 1984; Henderson-King and Stewart 1994).

Feminist consciousness among African American men is rarely explored (for an exception, see Awkward 1995), but several studies have examined their gender role attitudes. African American men are generally found to be supportive of women's work outside the home; on other gender role attitudes, such as shared housework and child rearing, they tend to straddle nonegalitarian and egalitarian gender role attitudes (Blee and Tickamyer 1995; Hatchett and Quick 1983; Ransford and Miller 1983; Wilkie 1993). As is the case for whites, African American men are less likely than African American women to support egalitarian gender role ideology (FigueiraMcDonough 1985; Ransford and Miller 1983). However, they are also more likely to acknowledge gender inequality and support collective action for women's issues than are white men and women (Gooley 1989; Gurin, Miller, and Gurin 1980; Kane 1992). The unique social location of African American men -- that is, their simultaneous experience of race oppression and gender privilege, in addition to less gender asymmetry in the economic and social organization of African American families -- may account for these patterns (Blee and Tickamyer 1995; Hunter and Davis 1992). Hunter and Davis (1992) found that African American men's conceptualizations of manhood indicated an endorsement of equality, justice, and free will in the public arena that was not gender specific. Yet, in the private sphere (i.e., family), they held ideas that supported both gender equality and traditional family responsibilities of men (e.g., provider, head of the family).

The work on both Black feminist thought and gender role attitudes suggests that African Americans' views about gender roles, gender relations, and gender inequality are, in part, connected to African Americans' unique culture and history. Because historical and 
contemporary racism limits the life chances of Black people regardless of gender and socioeconomic status, King (1975) argues that race will be more salient than any other system of stratification for African Americans. Consistent with these speculations, Gurin, Miller, and Gurin (1980) found that racial identity was more salient than gender identity for African American women. Yet, Robinson (1983), in her study of African American women, found that women who had strong race and gender consciousness were as likely as women who had only race consciousness to support Black empowerment and political organization. However, the level of internalization and integration of racial identity may affect support for feminist issues. Martin and Hall (1994), in their study of racial identity and gender consciousness, found that women who were in the immersion-emersion stage of racial identity development were significantly less likely to support feminist ideology. However, other stages of racial identity development were not significantly related to gender consciousness. How racial identity affects men's views on gender and gender inequality has received much less attention. The findings of Robinson (1983) and Martin and Hall (1994) suggest that the relationship between racial identity, gender, and feminist consciousness is more complex than choosing between race and gender.

To understand how the intersection of race and gender influences feminist ideology, additional studies are needed to explore African Americans' attitudes toward feminism. A number of studies examine patriarchal or egalitarian gender role ideology (Blee and Tickamyer 1995; Hatchett and Quick 1983). However, African Americans' critique of gender inequality and support for gender-based political organizing has received comparatively little empirical examination. Using the National Survey of Black Americans (Jackson 1991), we examine feminist attitudes among African American women and men. Specifically, this study addresses three questions: (1) Are there gender differences in African American views on gender inequality, egalitarian gender roles, and gender-based political organizing? (2) What factors are a catalyst for the development of feminist attitudes among African Americans? (3) Do factors predicting African American attitudes on feminist issues vary by gender and domain?

\section{IDENTIFYING PATHS TO FEMINIST IDEOLOGY: A HEURISTIC MODEL}

In this article, we focus on three issues that are central to the feminist movement: (1) recognition and critique of gender inequality in the private and public spheres, (2) destabilization of gender hierarchies (i.e., patriarchy) in the family and movement toward egalitarian gender roles, and (3) activism directed toward social and political change in the aforementioned areas. We do not examine a unified feminist identity or consciousness but rather explore African American attitudes in discrete domains that represent critical feminist issues. Figure 1 illustrates the conceptual model that guides this work. Feminist ideology includes three major domains: (1) the structural domain focuses on attitudes about gender inequality in the public sphere, (2) the ideological domain focuses on gender role ideology, and (3) the political domain focuses on attitudes about political activism to support women's issues. In our analysis, we examine the impact of historical location, economic resources, racial ecology, family context, and institutional involvement on African American women's and men's attitudes in these domains. 
With this model, we move beyond the exclusive focus on the effects of sociodemographic factors that has characterized much of the literature on race and gender role attitudes.

[Figure 1 Illustration Omitted]

\section{Historical Location}

Throughout the twentieth century, there have been significant shifts in ideology about gender and a woman's place in society, as well as significant shifts in women's employment, political participation, and family patterns. To measure exposure to these shifts, we examine the effects of birth cohort. Because the post-world War II birth cohorts (the baby boomers) came of age during a period of tremendous social change around race and gender, we contrast them with earlier birth cohorts. Generally, most studies find that younger respondents are more likely to endorse more egalitarian gender role attitudes in the private sphere (Thornton and Freedman 1979; Wilkie 1993). We expect a similar pattern for African Americans. However, older African Americans, who have witnessed the effectiveness of political movements and the instability of systems of inequality, may be more likely to endorse political action for women's issues than their younger counterparts.

\section{Economic Resources}

Generally, higher levels of education and income are related to less traditional attitudes about gender for both women and men (Hatchett and Quick 1983; Ransford and Miller 1983; Thornton and Freedman 1979). For women, labor force participation is positively associated with feminist attitudes (Thornton and Freedman 1979). Few researchers have examined the effect of employment status (i.e., whether employed or not) on men's attitudes about gender. However, African American men are more likely to experience unemployment and marginal employment than are White men. Historically, these differences reflect racial discrimination and segregation in the occupational sector (Harris 1982). Thus, African American men who are unemployed or who have experienced unemployment may be more cognizant of the impact of structurally based inequality on individual life chances.

\section{Racial Ecology}

Race is a defining construct in American society. It is a marker for ethnicity, shared history and culture, and a sense of peoplehood, and it represents exposure to structural inequality and the indignities associated with racial discrimination. Although race simultaneously taps oppression/privilege and ethnicity, a dual look at race is rare. Rather, post hoc cultural explanations are often used to understand observed racial differences in attitudes, or race is treated as a proxy for both social status and ethnicity. In this study, we take a more nuanced approach, focusing on two indices of racial ecology: racism and group affinity. 
Racism continues to be an "everyday" phenomenon for most African Americans (Essed 1990) and is associated with a range of outcomes, from lower levels of life satisfaction to higher mortality (Jackson et al. 1996). Exposure to racial discrimination and racially salient events may represent a significant catalyst for African American women and men to become cognizant of gender inequality, particularly in the public sphere (Kane 1992). Alternatively, such experiences may heighten race saliency to the exclusion of gender. In addition to the experience of racial discrimination, perceptions of white malevolence (e.g., whites wanting to keep Blacks down) may lead to a hypervigilance about race even if direct forms of racism have not been recently experienced.

Ethnic group affinity, to the extent that it represents a sense of common fate or cultural identification, may have competing effects on the development of feminist attitudes. The humanist flavor of core African American cultural traditions may encourage support of women's concerns even among men (e.g., Collins 1991; Gwaltney 1980; Hunter and Davis 1992). However, strong group affinity and immersion-emersion racial identity have been found to promote a race first, gender second attitude (Martin and Hall 1994).

Family Context

Mothers' employment and marital status are two aspects of family context that affect attitudes about gender. Ransford and Miller (1983) found that mothers' employment increased African American men's support for women's work outside the home, had no significant effect on other attitudes about gender, and was unrelated to women's attitudes (Ransford and Miller 1983). Beyond the employment status of mothers, Hershey (1978) found that Black respondents, whose mothers held blue-collar jobs, had more egalitarian views than those with mothers employed in white-collar occupations. These findings suggest that mothers' employment in class- and/or gender-oppressive occupations (e.g., domestic service, blue collar occupations) may increase awareness of gender inequality. We speculate that the type of work mothers do, be it housewife or salesclerk, will influence support for feminist ideology.

Findings on the impact of marital status on gender role attitudes have been mixed. Kane and Sanchez (1994) argue that the weak effect of family-level variables on gender role attitudes reflects differential stakes in gender inequality at home and in the public sphere. Because African American families are likely to depend on the wages of women, both women and men may have a greater stake in ending gender inequality in the public sphere. In addition, women's economic importance to the household economy may undermine endorsement of gender inequality at home. However, African Americans' perceptions of Black women's advantages in education and employment, coupled with the precarious economic position of many Black males, may counter the liberalizing effect of women's economic contribution on the gender role ideology for both women and men (Cazenave 1983; Cazenave and Smith 1991).

Institutional Involvement 
Interactions with public agencies and institutions of social control shape perceptions of race, class, and gender (Anderson and Collins 1992; Gordon 1990). This study examined three areas of institutional involvement: (1) contact with public agencies (welfare, unemployment offices, and the police), (2) involvement in the church, and (3) political participation. In large measure, the social welfare system is in place to address the product of social inequality; it also reifies an ideology about race, gender, and poverty that deemphasizes structural-based causes of social inequality (Baca Zinn 1989; Piven and Cloward 1971). For African American women, contact with the social welfare system may heighten recognition of gender inequality and increase activism to challenge these inequalities in the public sphere. In the private sphere, struggles with economic survival and social welfare agencies may foster a longing for a "traditional" household, one that includes a male breadwinner. For African American men, firsthand knowledge of a partner's, mother's, or sister's experiences with the indignities of welfare offices may heighten their awareness of gender inequalities in the public domain while increasing the desire to fulfill the breadwinner role and fostering support for nonegalitarian gender role ideology.

For welfare recipients, contact with welfare agencies is often overtly hostile (Sidel 1986); in contrast, unemployment offices may appear to be relatively benign. However, the experience of unemployment and subsequent contact with unemployment agencies is also an indicator of economic marginalization or limited employment opportunities. Trips to the unemployment office are often time-consuming, replete with paperwork, and unfriendly scrutiny by office staff. Despite their employment histories, assumptions about the poor easily spill over to the unemployed. But unlike "welfare," the ways in which gender constructions and family ideologies are at work in unemployment offices are less visible. For women, contact with unemployment offices may be less arduous, in part because it carries less stigma than other forms of public support. In contrast, contact with unemployment offices may signal to men and to agency staff a failure in the man's capacity to fulfill one of the most central male roles -- that of breadwinner, Hence, for women, we expect contact with employment offices to be only marginally related to support for feminist attitudes. Given that in the post-civil rights era economic marginality of men has often been used as the symbol of racial inequality and blocked opportunity, we expect that for men, contact with unemployment offices may heighten the salience of race-based economic inequality and diminish recognition of gender-based inequality.

Encounters with the police can range from aid and assistance to police harassment and physical abuse to lawful arrest. Historically, the police have been one of the instruments of racial oppression. Currently, emphasis on the social control of Black populations, particularly in urban areas, has continued the legacy of tense and uneasy relationships between African Americans and the police. In particular, young African American men have been victims of police harassment, violence, and brutality (Essed 1990; Gibbs 1988). For African American men, we expect that contact with the police will be related to less support for feminist ideology in both the public and private spheres because it will focus heightened attention on racial inequality and its impact on men's lives. For African American women, police contact may also heighten 
sensitivity to racialized injustice at the expense of gender. However, police contact could increase women's recognition of gender inequality and support for collective political action to challenge both racism and sexism.

African American churches have historically been a training ground for community leaders and are central sites of political and social activism (Lincoln and Mamiya 1990; Taylor and Chatters 1991). The church's emphasis on Black progress and social justice may heighten intolerance for all inequalities, including gender inequality. However, in the private sphere, religion-based family traditionalism may dampen egalitarian views of gender roles for both women and men.

Research suggests that African American political participation may be prompted by a recognition of their common fate as members of an oppressed group (Verba and Nie 1972). A sense of common fate may also contribute to the use of multiple modes of participation so that African Americans with the strongest sense of common fate attempt to change social inequalities through numerous strategies, from sit-ins to voting to contacting public officials (Gurin, Hatchett, and Jackson 1989). We expect that women's involvement in the political sphere will heighten support for feminist ideology, as we have seen with a number of Black women civil rights activists (Collins 1991; Giddings 1984). Although we expect political participation to affect men's attitudes, it is not clear what the direction of this effect may be.

The aim of this article is to explore potential pathways to the development of feminist ideology among African Americans. A number of studies have demonstrated significant support for feminist principles among African Americans. Most studies, however, typically look only at the effect of group membership (i.e., being Black or not) without explicit consideration of the context or content of those experiences that may make race a meaningful factor. In this study, we examine sociodemographic correlates of gender role ideology found in previous research and explore the impact of race-specific experiences and participation in social arenas that may have particular resonance for African American views on race and gender.

\section{METHODS AND MEASURES}

\section{The Sample}

The National Survey of Black Americans (NSBA) was the first national multistage household probability sample of self-identified Black Americans living in the continental United States. In addition to being the first nationally representative sample of Black Americans, NSBA is unique in several regards. It was the first time a large-scale survey was developed to assess the thoughts, feelings, attitudes, and experiences of African Americans from a culturally responsive perspective. The survey was wide-ranging, touching on all aspects of life in Black America, including work, family life, racial identity, and physical and mental health (see Jackson 1991 for a detailed description of (NSBA). There were 2,107 adults, ranging in age from 18 to 101, interviewed in their homes by African American interviewers in 1979-80. The mean age for male respondents was 42.8 and 43.4 for women. Fifty-three percent of the men and 35 percent of the 
women were currently married. The mean educational level for both women and men was eleven years. Mean household income was \$8,000 to \$9,999 (in 1979 dollars). Men had significantly higher mean household income than women. More than one-half (54.2 percent) of women and 71.7 percent of men were employed.

The Model

We examine three issues central to feminism: (1) recognition and critique of gender inequality, (2) egalitarian gender roles, and (3) political activism for the rights of women. Based on the model in Figure 1, we examine the impact of historical location, economic resources, racial ecology, family context, and institutional involvement on African American women's and men's attitudes in these domains.

Dependent Variables

We examined respondent positions on three feminist issues: (1) sex discrimination, (2) gender role ideology, and (3) political organizing for women. Respondent position on sex discrimination was measured using the following question: "Do you think sex discrimination is a real problem for Black and White women in this country?" Response categories -- yes (1) or no (0) -- were dummy coded. Egalitarian work and family gender role ideology were measured by the following items: "Both men and women should share equally in child care and housework" and "Both men and women should have jobs to support the family." Response categories ranged from strongly agree to strongly disagree on a 4-point scale. Higher scores indicated an endorsement of egalitarian gender role ideology. To examine strong support for egalitarian gender role ideology, we used a median split and created a dichotomous variable. Scoring above the median was coded as 1 , and scoring below the median was coded as 0 . Respondent position on political organizing was measured by the following item: "Is it more important for Black women to fight for the rights of all Black people or to fight for the rights of all women, or are both equally important?" Responses that included organizing for women with or without Blacks were coded as 1 ; the category that excluded women was coded as 0 .

Independent Variables

Historical location and economic resources. Historical location was measured by birth cohort. Baby boomers, born 1947 and later, were contrasted with earlier birth cohorts. Economic resources included three indices: education, household income, and employment status. Education was measured by the number of years of education completed. Household income included income support from all sources reported by respondents. Because we were interested in the impact of current employment, full- or part-time employment was coded 1 , and not currently employed was coded 0.

Racial ecology. Racial ecology was measured in three areas: (1) experience of racism, (2) perceptions of white malevolence/discriminatory intent, and (3) Black group affinity. It should 
be noted that although each construct is an important component of racial ecology, they are conceptually discrete and were not combined into a single scale (Jackson et al. 1991). Experience of racial discrimination was measured by the following item: "In the past month, have you or your family been treated badly because of your race?" Responses were coded (1) yes and (0) no. Respondent perception of Whites' discriminatory intent was measured by the following item: "On the whole, do you think White people want to see Blacks get a better break, or do they want to keep Blacks down, or don't they care one way or the other?" Endorsement of the view that whites want to keep Blacks down was coded 1; other categories were coded 0. Black group affinity (i.e., feelings of closeness to other African Americans) was measured with the following question: "How close do you feel in your ideas and feelings about things to Black people who are poor, religious, young, middle class, working class, older, elected officials, and professional Black people?" Responses ranged from very close to not close at all.

Family context. Marital status and mother's employment were used as indicators of family background and context. Marital status was coded 1 if currently married (legal and common law) and 0 if not currently married. Based on census classifications, mothers' employment was divided into six agriculture, personal services (public and private), clerical/retail, manufacturing, professional -- and unspecified occupations. When respondents indicated that their mothers were employed but did not specify the occupational category, mother's employment was coded as occupation unspecified. Mothers who worked at home only (housewives) were contrasted with other types of employment.

Institutional involvement. Three areas of institutional involvement were examined: public agency contact, church participation, and political participation. Public agency contact was measured by the following item: "Have you ever gone to a place where you get unemployment benefits, retirement benefits, welfare services (including general assistance and AFDC), worker's compensation, employment assistance, the police, the courts, and job training?" Responses were coded 1 if they had contact and 0 if they had no contact. Church participation was measured by two items: "How often do you go to church?" and "How often are you involved in other churchrelated activities?" Response categories ranged from nearly every day to never. Responses were summed, and each respondent received a mean score (Ellison 1992). Political participation was measured by counting the number of political activities in which respondents reported involvement. Respondents were asked about four types of political participation: presidential voting, state and local voting, campaign activity, and contacting a public official. Respondents received a score of 1 for each political activity they participated in. These scores were summed for a measure of political participation, with values ranging from 0 to 4 .

\section{ANALYSES}

Table 1 compares African American women's and men's attitudes about sex discrimination, egalitarian gender role ideology, and political organizing for women. There were no gender differences in African Americans' view of sex discrimination. Almost 48 percent of women and 
48.1 percent of men felt that sex discrimination was a problem for Black and White women in the United States. Both women $(\mathrm{M}=3.25, \mathrm{SD}=.59)$ and men $(\mathrm{M}=3.03$, $\mathrm{SD}=.624)$ tended to support egalitarian gender role ideology, with women being significantly more supportive than men ( $\mathrm{t}=7.99$, $\mathrm{p}$ [is less than] .05). Women were also more likely than men to have scores above the median. More than 48 percent of women and 34.6 percent of men scored above the median on support for egalitarian gender roles. Women and men were also supportive of women organizing to fight for their rights. Respondents did not differ in their support by gender; [Chi.sup.2] $(1,2054)=1.84$, $\mathrm{p}$ [is greater than or equal to] .05. More than 80 percent of both women and men endorsed political organizing for women's issues. Most women (89.6 percent) and men (86.8 percent) felt it was equally important for African American women to organize around both race and gender. About one in ten men (13.1 percent) and women (10.4 percent) felt that Black women should work on women's rights exclusively.

\section{[Table 1 Omitted]}

Logistic regression analyses were used to examine the effect of historical location, economic resources, family context, racial ecology, and institutional involvement on African Americans' views on sex discrimination, gender role ideology, and political organizing for women's fights (Table 2). For each dependent variable, the model was examined separately for women and men.

[Table 2 Omitted]

Structural Domain: Sex Discrimination Is a Problem

The analyses indicated that economic resources, family context, political participation, and, to a lesser degree, indicators of racial ecology influenced attitudes about sex discrimination. The variables affecting respondents' positions on gender inequality in the public sphere varied by gender. For women, those who had higher educational levels and higher household incomes and who were politically active were more likely to view sex discrimination as a problem. Women who perceived racial discriminatory intent among whites tended to endorse the view that sex discrimination is a problem. Among men, those who were more highly educated and married were more likely to view sex discrimination as a problem. Men whose mothers worked in agriculture (in contrast to being a housewife) tended to be less likely to consider sex discrimination a problem.

Ideological Domain: Egalitarian Work and Family Gender Role Ideology

Logistic regression analyses indicated that birth cohort, indices of family context, economic resources, racial ecology, and institutional involvement were related to the likelihood of support for egalitarian gender role ideology. Variables affecting respondents' endorsement of egalitarian gender role ideology varied by gender. For women, baby boomers who were employed were more likely to endorse egalitarian gender role attitudes. For men, those with high Black group affinity, lower levels of church participation, and contact with unemployment agencies were 
more likely to endorse egalitarian gender role ideology. There was also a trend for men whose mothers worked in clerical/retail occupations (in contrast to housewives) to be more likely to support egalitarian gender roles.

\section{Political Domain: Political Organizing for Women}

The analyses indicated that family context, institutional involvement, and racial ecology affect the likelihood of support for political organizing for women's rights. Once again, predictors of the endorsement of political organizing for women also varied by gender. For women, those who believed that whites want to keep Blacks down and who did not have contact with welfare agencies were less likely to support political organizing for women's rights. There was also a trend for those who had recently experienced racism to be less likely to advocate gender-based organizing. Among men, those whose mothers were housewives (in contrast to mothers working in clerical/retail occupations), who did not have contact with welfare agencies, and who had contact with the police were more likely to endorse political organizing for women. As the level of Black group affinity increased, men were less likely to support political organizing for women's issues. Men who had contact with unemployment agencies tended to be more likely to support gender-based political organizing.

\section{SUMMARY AND DISCUSSION}

The salience of racial inequality for African Americans and the political tensions with the feminist movement have fueled the view that African Americans are unlikely to support feminism or have feminist attitudes. In this article, we examined African Americans' views on issues that have been central to the feminist movement. Our findings suggest there is significant support for feminist ideology and an uneasiness with gender inequality among African Americans. These findings are consistent with a number of studies that have explored African American views on gender in the public and private spheres (e.g., Blee and Tickamyer 1995; Gooley 1989; Hunter and Davis 1992; Kane 1992; Wilkie 1993).

African American women and men also tended to have similar positions on the feminist issues examined, but how they arrived at these ideological positions varied. As suggested by other studies (Ransford and Miller 1983; Thorton and Freedman 1979), income and education had a liberalizing effect on both women's and men's attitudes about sex discrimination. Among women, higher levels of household income and education heightened awareness of gender inequality, perhaps via women's own experiences in the labor force. For men, the effect of education coupled with marriage suggests that wives may be a catalyst for men's awareness of structural-based gender inequality. That is, men may directly experience the impact of gender inequality through the depressed wages and limited economic opportunities of their wives. Because many African American families also depend on wives' employment for economic survival or to reach middle-class status (Wilkie 1993), sex discrimination may be very salient for married men. These findings are consistent with Wilkie's (I 993) suggestion that African 
American men are more liberal in their views about women's work and the provider role than White and Hispanic men because of African American women's position in the family economy.

Although both women and men endorsed egalitarian views of work and family roles, women were somewhat more liberal than men. Among women, baby boomers who were employed most strongly supported egalitarian work and family roles, a finding consistent with studies of white Americans (e.g., Thornton and Freedman 1979). Although there were not any variations by cohort for men, men who were more involved in church were less likely to support egalitarian gender roles. Interestingly, there was also a link between men's egalitarian gender role attitudes, race (i.e., group affinity), and contact with unemployment agencies. These two factors (group affinity and unemployment) may be indices of racial ecology that respectively measure men's sense of themselves as African Americans and men's struggles with economic marginality. Exposure to race-based social inequalities and a sense of common fate may facilitate the development of a critique of inequality in the public and private spheres.

In both academic and lay forums, it has been argued that racism and the lack of economic opportunity undermine Black manhood and masculine authority in African American families. While there is no question that economic hardship takes its toll on families regardless of race (Elder 1978; McLoyd 1990), the functioning of men and patriarchal authority have been a central part of the discussion on African American families and economic well-being (Frazier 1939; Moynihan 1965; Wilson 1987). African American men are often cast as having few positive proactive adaptive strategies to handle the "crisis" associated with a diminished primary provider role (Hunter and Davis 1992). However, our findings suggest that men's experiences with unemployment may facilitate a recognition of the importance of both women and men inside and outside the home, particularly in difficult times. Hence, one response to a threatened male breadwinner role is a shift in gender role attitudes.

Racial ecology emerged as an important factor in the endorsement of political organizing for women's issues across gender. For women, perceptions of the racist intent of whites and experiences with racial discrimination drove their rejection of interracial gender-based political organizing. These findings could be viewed in two ways. First, the identification of the women's movement with white women may lead African American women who are distrustful of whites to distance themselves from a political movement that is perceived to further advantage whites. Second, the problem of racial stratification may be more salient for women who have a more heightened sense, either through experience or perception, of racial oppression and discrimination. For men, the perception of whites' racist intent and the experience with racial discrimination were not significantly related to their views on gender-based political organizing. However, higher levels of Black group affinity decreased the likelihood of support for organizing around women's rights.

While women appear to be pushed away from gender-based political organizing via aversive (real or perceived) race relations, it is men's group identification with African Americans that 
undermines support for interracial political organizing for women's issues. These patterns for men may reflect a form of Black nationalism where race and peoplehood are paramount. From a Black nationalist perspective, to politically organize for the interests of Blacks to the exclusion of gender is in the interest of the entire Black community, including Black women. Although the majority of respondents supported interracial political organizing for women's rights, these findings suggest that there are ideological and social psychological factors that can heighten the saliency of racial interests to the exclusion of gender. However, indicators of racial ecology mattered most for political action; for other domains, it had either no effect or led to greater support for feminist positions. Beyond racial ecology, it was expected that political participation would be related to support for gender-based political organizing, but this was not the case. However, women who were politically active were more likely to see sex discrimination as a problem. Perhaps these women in turn would be more likely to support political organizing for women's issues.

Public agency contact (i.e., welfare, police, unemployment) also affected support for political organizing across gender. We examined contacts with welfare, unemployment agencies, and the police because these arms of state are sources of social control, address the consequences of social inequality, and reflect fundamental ideologies about race, gender, and class. Despite the importance of these institutions in the lives of Americans, particularly African Americans, empirical investigations of the linkages between institutional contact and feminist ideology have not been conducted to our knowledge. We found that women who had contact with welfare agencies were more likely to support political activism for women's rights. The indignities associated with welfare and the ways in which African American women's lives are shaped by the racialization and feminization of poverty may lead Black women to be more supportive of both race and gender-based political organizing. In contrast, we found that men's contact with welfare led to decreased support for gender-based organizing. For men, contact with welfare agencies, particularly if it is negative, may not be perceived as gendered but rather primarily a function of racial stratification. Alternatively, men may see welfare as one of the advantages that the state affords women at the expense of African American men, and the remedy is to focus political organizing exclusively around race. Indeed, Cazenave and Smith (1991), in a small study of working-class African Americans, found that a substantial minority of their respondents felt Black women were more advantaged than Black men.

We expected that experiences with the police and unemployment agencies, because they are more likely to focus attention on racism and the plight of African American males, would depress support for political organizing for women. This hypothesis was not confirmed. In fact, men who had contact with the police were more likely to support political organizing for women's rights. Although we do not know the nature of these contacts and their resolution, these findings suggest that experiences with the police and unemployment agencies do not undermine support for gender-based political organizing. Further, these experiences may be catalysts for increased support for women's political activism. 
Over the past two decades, there has been increased interest in theorizing about multiple identities and political loyalties in feminist scholarship. The findings from this study suggest that African Americans' support for feminist ideology is tied both to gender and a confluence of experiences that are connected to race. In addition, the impact of other measures of social location (e.g., education, income, cohort), family background, experiences with public institutions, and work indicate there are multiple catalysts and barriers to the development of feminist ideology. Variations in the predictors of feminist attitudes across domains (i.e., structural, political, ideological) suggest that domain-specific models may be more useful for explaining different components of feminist ideology than a unitary model. Similarly, given the complexity of feminist epistemology, comprehensive measures of feminist ideology are also needed. The differences and similarities in African American attitudes by gender also highlight the need for empirical studies of women and men within and across racial-ethnic groups. Despite the body of work on African American women and feminist thought, there have been few empirical investigations or theoretical discussions of feminist ideology or consciousness among Black men. Our findings suggest that there are critical events and experiences in Black men's lives that differ from the experiences in women's lives, which can support the development of feminist attitudes. Importantly, this study illustrates both the potential foundations of feminist thought among African Americans and the multiple influences on individuals' attitudes about gender (in)equality and political organizing for women's rights.

\section{REFERENCES}

Anderson, Margaret, and Patricia Hill Collins. 1992. Race, class and gender: An anthology. Belmont, CA: Wadsworth.

Awkward, Michael. 1995. A Black man's place(s) in Black feminist criticism. In Representing Black men, edited by M. Blount and G. Cunningham. New York: Routledge Kegan Paul.

Blee, Kathleen, and Ann Tickamyer. 1995. Racial differences in men's attitudes about gender roles. Journal of marriage and the Family 57:21-30.

Cazenave, Noel. 1983. A woman's place: The attitudes of middle-class Black men. Phylon 94 (1):12-32.

Cazenave, Noel, and R. Smith. 1991. Gender differences in the perception of Black male-female relationships and stereotypes. In Black families: Interdisciplinary perspectives, edited by Howard Chatham and James Stewart. New Brunswick, NJ: Transaction Books.

Collins, Patricia. 1991. Black feminist thought. New York: Routledge Kegan Paul.

Combahee River Collective. 1982. A Black feminist statement. In But some of us are brave, edited by G. Hull, B. Scott, and B. Smith. Old Westbury, NY: Feminist Press. 
Elder, Glen. 1978. Family history and the life course. In Transitions, edited by Tamara Hareven. New York: Academic Press.

Ellison, Christopher. 1992. Military background, racial orientations, and political participation among Black adult males. Social Science Quarterly 73 (2):360-78.

Essed, Philomena. 1990. Everyday racism: Reports from women of two cultures. Claremont, CA: Hunter House.

Figueira-McDonough, Josefina. 1985. Gender, race, and class: Differences in levels of feminist orientation. Journal of Applied Behavioral Science 21 (2):121-42.

Frazier, E. Franklin. 1939. The Negro family in the United States. Chicago: University of Chicago Press.

Gibbs, Jewelle Taylor. 1988. Young, Black and male in America. Dover, MS: Auburn.

Giddings, Paula. 1984. When and where I enter. New York: Bantam.

Gooley, R. 1989. The role of Black women in social change, Western Journal of Black Studies 134:165-72.

Gordon, Linda. 1990. Women, the state, and welfare. Madison: University of Wisconsin.

Gurin, Patricia, Shirley Hatchett, and James Jackson. 1989. Hope and independence: Blacks' response to electoral and party politics. New York: Russell Sage.

Gurin, Patricia, Arthur Miller, and Gerald Gurin. 1980. Stratum identification and consciousness. Social Psychology Quarterly 43 (1):33-47.

Gwaltney, John. 1980. Drylongso: A self-portrait of Black America. New York: Random House.

Harris, William. 1982. The harder we run: Black workers since the Civil War. New York: Oxford University Press.

Hatchett, Shirley, and Alida Quick. 1983. Correlates of sex role attitudes among Black men and women: Data from a national survey of Black Americans. Institute for Urban Affairs and Research 9 (2): 1-11.

Henderson-King, Donna, and Abigail Stewart. 1994. Woman or feminist? Assessing women's group consciousness. Sex Roles 31:505-16.

Hershey, Marjorie. 1978. Racial differences in sex-role identities and sex stereotyping: Evidence against a common assumption. Social Science Quarterly 58:583-96.

Hooks, bell. 1981. Ain't I a woman: Black women and feminism. Boston, MA: South End Press. 
Hunter, Andrea, and James Davis. 1992. Constructing gender: An exploration of Afro- American men's conceptualization of manhood. Gender \& Society 6 (3):464-79.

Jackson, James. 1991. Life in Black America. Newbury Park, CA: Sage.

Jackson, James, Wayne McCullough, Gerald Gurin, and Clifford Broman. 1991. Race identity. In Life in Black America, edited by J. Jackson. Newbury Park, CA: Sage.

Jackson, James, T. Brown, D. Williams, M. Torres, S. Selters, and K. Brown. 1996. Perceptions and experiences of racism and the physical and mental health status of African Americans: A thirteen-year national panel study. Ethnicity and Disease 6 (1/2):132-47.

Kane, Emily. 1992. Race, gender, and attitudes toward gender stratification. Social Psychology Quarterly 55 (3):311-20.

Kane, Emily, and Laura Sanchez. 1994. Family status and criticism of gender inequality at home and at work. Social Forces 72 (4):1079-1102.

King, Deborah. 1988. Multiple jeopardy, multiple consciousness: The context of a Black feminist ideology. Signs: Journal of Women in Culture and Society 14 (1):42-72.

King, Mae. 1975. Oppression and power: The unique status of Black women in the American political system. Social Science Quarterly 56:117-28.

Lincoln, Charles, and Lawrence Mamiya. 1990. The Black church in the African American experience. Durham, NC: Duke University Press.

Martin, Juanita, and Gordon Hall. 1994. Thinking Black, thinking internal, thinking feminist. Journal of Counseling Psychology 39:509-14.

McLoyd, Vonnie. 1990. The impact of economic hardship on Black families and children: Psychological distress, parenting, and socioemotional development. Child Development 61:31146.

Moynihan, Patrick. 1965. The Negro family: The case for national action. Washington, D.C.: U.S. Department of Labor, Office of Policy Planning and Research.

Piven, Frances Fox, and Richard Cloward. 1971. Regulating the poor: The functions of public welfare. New York: Random House.

Ransford, H. Edward, and Jon Miller. 1983. Race, sex, and feminist outlooks. American Sociological Review 48:46-59.

Robinson, Debbie. 1983. The effects of multiple group consciousness among Black women on perceived Black power. Unpublished paper, University of Michigan. 
Sidel, Ruth. 1986. Women and children last: The plight of poor women in affluent America. New York: Viking.

Taylor, Robert, and Linda Chatters. 1991. Religious life. In Life in Black America, edited by James Jackson. Newbury Park, CA: Sage.

Terrelonge, Pauline. 1984. Feminist consciousness and Black women. In Women: A feminist perspective. 3d ed. Edited by Jo Freeman. Palo Alto, CA: Mayfield.

Thornton, Arland, and Deborah Freedman. 1979. Changes in the sex role attitudes of women, 1962-1977: Evidence from a panel study. American Sociological Review 44:831-42.

Verba, Sidney, and Norman Nie. 1972. Participation in America: The view from the top. Cambridge, MA: Cambridge University Press.

Wilcox, Clyde. 1989. Race, gender role attitudes and support for feminism. Western Political Quarterly 43:113-21.

--. 1990. Black women and feminism. Women and Politics 10 (3):65-84.

Wilkie, Jane. 1993. Changes in U.S. men's attitudes toward the family provider role, 1972-1989. Gender \& Society 7 (2):261-79.

Wilson, William. 1987. The truly disadvantage: The inner city, the underclass, and public policy. Chicago: University of Chicago Press.

Zinn, Maxine Baca. 1989. Family, race, and poverty in the eighties. Signs: Journal of Women in Culture and Society 14:856-74.

Andrea G. Hunter Ph.D., is an assistant professor in the Department of Psychology and the Women's Studies Program at the University of Michigan and is faculty associate in the Program for Research on Black Americans at the Institute for Social Research. Her research centers on African American families, gender and the life course, and the linkages between families, social structure, and culture.

Sherrill L. Sellers is a PhD candidate in the Joint Social Work and Sociology Program at the University of Michigan. She is affiliated with the Center on Poverty, Risk and Mental Health and the Program for Research on Black Americans at the Institute for Social Research. Her research interests include the life course, health consequences of social inequalities, and intergenerational relations. Her specialization is in gender social mobility, and mental health. 